\title{
Environmental Health Factors and Sexually Dimorphic Differences in Behavioral Disruptions
}

\author{
Cheryl S. Rosenfeld • Brian C. Trainor
}

Published online: 18 September 2014

(C) Springer International Publishing AG 2014

\begin{abstract}
Mounting evidence suggests that environmental factors - in particular, those that we are exposed to during perinatal life - can dramatically shape the organism's risk for later diseases, including neurobehavioral disorders. However, depending on the environmental insult, one sex may demonstrate greater vulnerability than the other sex. Herein, we focus on two well-defined extrinsic environmental factors that lead to sexually dimorphic behavioral differences in animal models and linkage in human epidemiological studies. These include maternal or psychosocial stress (such as social stress) and exposure to endocrine-disrupting compounds (such as one of the most prevalent, bisphenol A [BPA]). In general, the evidence suggests that early environmental exposures, such as BPA and stress, lead to more pronounced behavioral deficits in males than in females, whereas female neurobehavioral patterns are more vulnerable to later in life stress. These findings highlight the importance of considering sex
\end{abstract}

\section{S. Rosenfeld}

Department of Biomedical Sciences, University of Missouri, 440F

Bond Life Sciences Center, Columbia, MO, USA, USA

\section{S. Rosenfeld}

Department of Bond Life Sciences Center, University of Missouri, 440F Bond Life Sciences Center, Columbia, MO, USA, USA

\section{S. Rosenfeld ( $\triangle)$}

Department of Genetics Area Program, University of Missouri, 440F

Bond Life Sciences Center, Columbia, MO, USA, USA

e-mail: rosenfeldc@missouri.edu

\section{B. C. Trainor}

Department of Psychology, University of California, Davis,

CA 95616, USA

e-mail: bctrainor@ucdavis.edu

B. C. Trainor

Center for Neuroscience, University of California, Davis, CA 95616, USA differences and developmental timing when examining the effects of environmental factors on later neurobehavioral outcomes.

Keywords Developmental Origins of Health and Disease . In Utero Environment - Stress - Endocrine Disruptors . Bisphenol A · Cognition - Anxiety - Sexual Selection . Social and Reproductive Behaviors - Glucocorticoids . Anhedonia - Sex Differences · Gonadal Hormones

\section{Introduction}

The notion that many adult diseases originate from early environmental changes has gained currency in the past decade $[1-3,4 \bullet]$. Several systems - in particular, the reproductive and central nervous systems - are programmed by developmental exposure to steroid hormones [5-12] and genes carried on the Y chromosome [13•]. Sexually dimorphic responses to environmental changes might originate from variable placental responses to environmental exposures, which may buffer the fetus of one sex more than the other [14-16]. For the purpose of this review, a sexually dimorphic response will be considered a phenotypic effect that either differs in absolute occurrence between the sexes (with a response present in one sex but absent in the other) or a significant difference in the magnitude of the intensity. For instance, early reports indicated that certain toxicants and food additives lead to kidney tumors in male but not female rats or mice [17, 18]. From these original reports, extrinsic factors have been reported to lead to varying degrees of sexually dimorphic responsesincluding, most recently, in neurobehavioral endpoints, which will be the primary focus of this review. With the National Institutes of Health (NIH) requesting a stronger emphasis on reporting health outcomes in both sexes, it is likely that research in the coming decades will further elucidate how 
various environmental cues result in dramatic sexually dimorphic differences.

Sexually selected cognitive traits might be especially vulnerable to extrinsic environmental changes [19]. As originally defined by Darwin [20], such traits promote intrasexual competition and intersexual choice of mating partners [20, 21]. Female mating preferences can drive the evolution of anatomical or behavioral traits in males and, in some cases, male mating preferences have been found to exert selection on female traits [22]. Expression of sexually selected behaviors in mature animals is programmed by developmental (fetal and neonatal or perinatal) exposure of the brain to steroid hormones (an organizational effect) and is maintained later in life by these same hormones - in particular, testosterone (an activational effect) $[19,23]$.

Environmental factors may abolish or augment the normal sex-specific brain programming or organizational effects necessary for sexually selected and other sexually dimorphic behaviors, leading to later behavioral deficits $[1,19,24 \bullet \bullet$, 25]. These changes could have a long-lasting impact on how endogenous hormones act in mature individuals.

The cerebral cortex, hippocampus, and hypothalamus (including the arcuate, ventromedial, and paraventricular nuclei) are key brain regions that demonstrate pronounced sexually dimorphic differences in neural programming [26]. While androgen receptors (ARs) are expressed in these regions, many testosterone-mediated neurobehavioral effects are due to aromatization of testosterone to estrogen [27-30]. Hippocampal development is dependent upon this steroid conversion [27, 28]. Being lipophilic, these circulating steroid hormones, along with many endocrine-disrupting compounds (EDCs), can easily cross the blood-brain barrier. Endogenous and exogenous steroids bind to their cognate receptors, including ARs, estrogen receptor (ESR) 1, and ESR2, which are widely expressed in these brain regions [31-37]. There are also sex differences in the expression of these steroid hormone receptors in the brain. For example, in the medial preoptic area (mPOA) of males, the Esr 1 promoter is hypermethylated and Esrl expression is reduced, relative to that in females [38]. In contrast, neonatal female pups treated with estradiol exhibit a masculinized DNA methylation pattern for Esrl. It is also clear that EDCs, such as bisphenol A (BPA), can alter, in a sex-dependent manner, the neural expression of Esrl and Esr2 $[33,39,40]$, which may be one mechanism by which these extrinsic factors can either ablate or heighten sex-specific behavioral responses.

While various environmental factors have been linked to sex-specific disruptions, this review will focus on two wellcharacterized factors: perinatal exposure to EDCs, with the prototype being BPA, and psychosocial stress. We will consider how such environmental factors affect sexually selected behavioral traits in adults, including cognition and reproductive and emotional behaviors.

\section{Sexually Dimorphic Behavioral Differences Associated with Endocrine-Disrupting Compounds}

\author{
Bisphenol A (BPA)
}

Most EDCs are manufactured chemicals [41], and, of these, BPA is one of the most mass produced, with production exceeding 8 billion pounds per year [42, 43]. One known action of BPA is binding and activation of ESRs [43], leading to disrupted development of hormone-dependent systems. The pervasiveness of this chemical predicts widespread and continued exposure of animals and humans [42, 43]. BPA is almost ubiquitously found in people; it is detectable in the urine of $93 \%$ of the US population [44], as well as in fetal plasma, placental tissue [45], and breast milk [46]. Results from animal models and human studies indicate that exposure to BPA induces sex-specific effects in three general categories: (1) cognitive function, (2)emotional function (e.g., anxiety), and (3)sociosexual behaviors (Table 1).

Sexually mature, polygamous male deer mice (Peromyscus maniculatus bairdii) exhibit enhanced spatial navigational learning and memory, allowing them to locate potential female partners, which are widely dispersed throughout the environment [47]. Consequently, this behavior might be considered a sexually selected cognitive trait, which requires prenatal exposure to testosterone and photoperiod-dependent increases in this same hormone [47, 48]. Developmental exposure to environmentally relevant concentrations of BPA or ethinyl estradiol (EE) through the maternal diet compromises this behavior in males, as determined when both sexes are tested at adulthood in a dry-land spatial navigation maze (a Barnes maze) [24••, 49]. Under the notion that BPA may act through its weak binding of ESR1/ESR2 [43], the US Food and Drug Administration (FDA) has mandated that any study that is to be considered in influencing policy decisions must include EE as a positive control.

Male imprinting control region (ICR) mice exposed to BPA as adults also exhibit impaired spatial and passive avoidance memory, as evidenced by their performance in the Morris water maze and footshock testing, whereas these deficiencies are not observed in exposed females [50]. These differences may be mediated by early exposure to estrogens or testosterone, which affects development of the hippocampus and cerebral cortex [48, 51-53].

In control, non-treated female deer mice, spatial navigational ability is not enhanced when they become sexually mature, as increased exploration and expansion of the home range may be disadvantageous, with an increased predation risk. However, females that are developmentally exposed to a low dose of BPA or EE at doses comparable to human exposure exhibit masculinized or increased spatial abilities and exploratory behaviors $[24 \bullet \bullet, 49]$. 


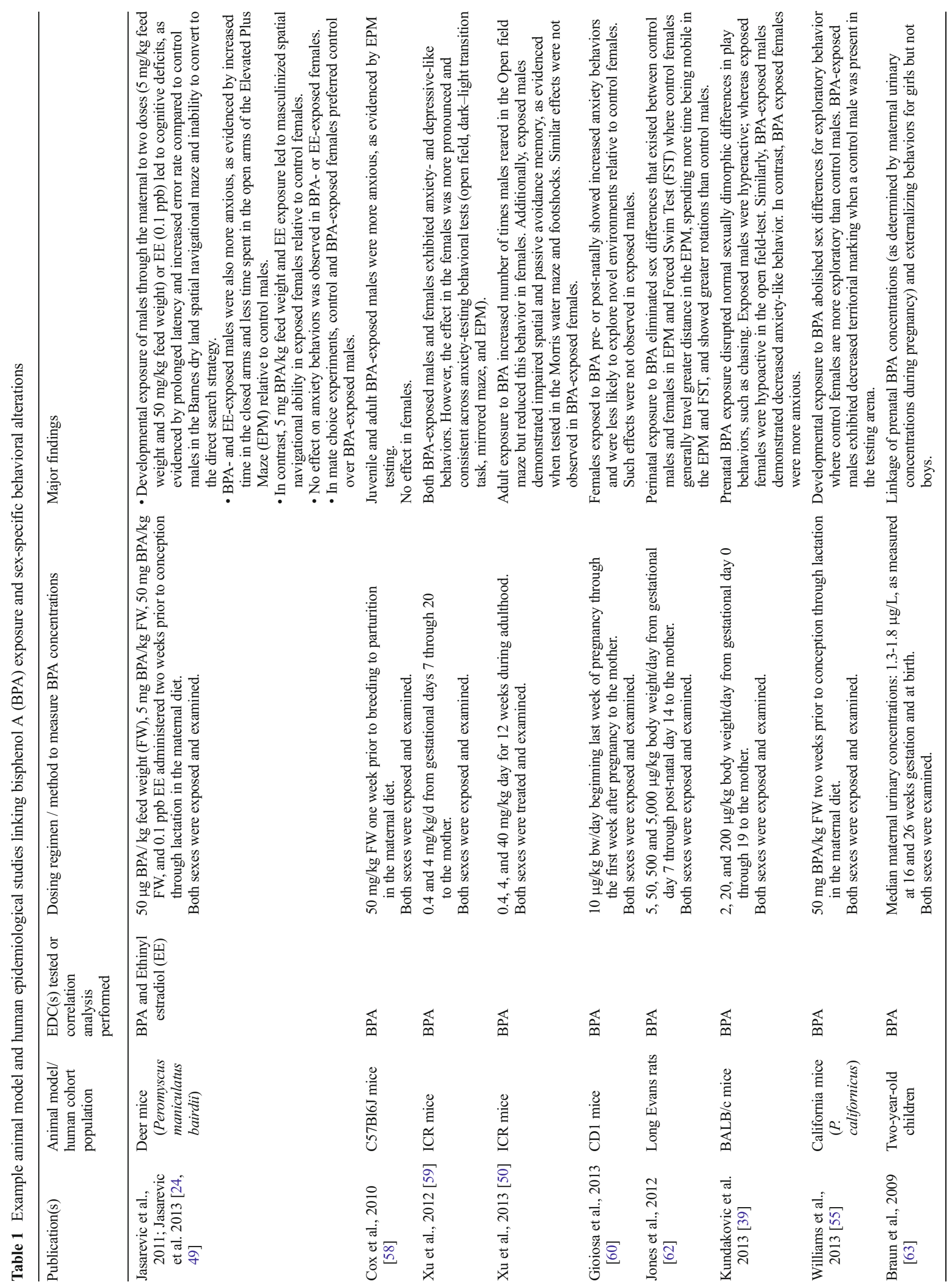


Male California mice (Peromyscus californicus) generally pair-bond with a single female, and thus they do not possess enhanced spatial navigational ability relative to females [54]. Consistently, developmental exposure to BPA or EE has not altered spatial navigation in male or female California mice [55]. However, BPA exposure abolished typical sex differences in the exploratory behaviors of this species, with exposed females spending less time in the open arms of the maze ( $30 \mathrm{~cm}$ platforms lacking barriers on each side, comparable to the animal being placed on a diving board $100 \mathrm{~cm}$ above the ground) - a positive index of exploration - than control females and an equivalent amount of time to that of control males.

Although BPA disruptions in exploratory, anxiety-like, and depressive-like behaviors have been found to differ across contrasting species of rodents, a common thread is that BPA exposure reduces sex differences in behaviors. In the deer mice studies described above, BPA or EE exposure during development increased anxiety-like behavior in elevated-plusmaze males but not in females $[56,57]$. Similar sexually dimorphic responses were seen in C57BL6J mice, as developmental BPA exposure increased anxiety-like behavior in males but not in females [58]. In both of these species, control females showed higher levels of anxiety-like behavior than males. In contrast, studies with ICR, BALB-c, and CD1 mice reported that developmental BPA exposure increased anxietylike behavior in females but not in males [59-61]. Similar disruptions of typical sexually dimorphic differences in exploratory behaviors have been reported in Long-Evans rat females exposed to BPA during the perinatal period [62]. In all four strains, control males showed higher levels of anxiety like behavior than females.

In humans, the primary neurodevelopmental types of outcomes associated with increased maternal or childhood urinary BPA concentrations have been emotional behaviors. One study reported that elevated maternal urinary BPA concentrations between 16 weeks of gestation and birth were linked to increased externalizing behaviors (e.g., hyperactivity and aggression) in girls but not in boys at 2 years of age [63]. The absence of an effect in boys might be related to the developmental stage that was examined. Another epidemiological study focusing on older children (3-5 years of age) reported that higher maternal BPA concentrations in urine at 34 weeks of gestation and higher child urinary BPA concentrations were associated with increased externalizing behaviors in boys, whereas the opposite correlation was reported in girls [64]. Examination of children at even later ages (7- to 9-year-olds) also demonstrated trends for an interaction between prenatal BPA exposure and externalizing problems, with higher BPA concentrations being linked to increased externalizing problems in boys but not in girls [65]. Externalizing problems in boys become more prevalent at 5-7 years of age, which may partially explain why the effects of BPA on externalizing 
problems were observed only in studies with older children [66]. Other environmental factors are also likely to be important, as there was variability across the studies in socioeconomic status. All of the studies reviewed above considered internalizing problems as well, but there was little consistency in how these problems were associated with BPA across the studies. It is not clear whether these differences are due to intrinsic sex-specific behavioral vulnerabilities to environmental factors or whether BPA is accentuating already existing sexually dimorphic behavioral differences.

BPA exposure disrupts several sociosexual behaviors in various rodent models. In mate choice experiments, both BPA and control female deer mice preferred control males over males that had been developmentally exposed to BPA [24*0]. Male California mice must defend their territory and their mate from male intruders by engaging in territorial marking. However, BPA-exposed California male mice exhibited suppressed territorial marking when control males were present in the test arena [55]. Prenatal exposure of BALB-c mice disrupted normal sexually dimorphic differences in play behavior [39]. It remains to be determined whether these behavioral changes equate to altered male reproductive success. It is also not clear how well the various sex-specific behavioral differences will translate to humans.

Another concern relates to potential differences in metabolism of BPA between rodents and humans. Both adult rodents and primates primarily metabolize BPA through glucuronidation of BPA via UDP-glucuronosyltransferases (UGTs). However, clearance of BPA in primates is generally through urinary excretion, whereas the biliary-fecal route is the primary route of excretion in rodents [67, 68]. Other potential pharmacokinetic differences across species include metabolism of BPA through sulfonation, which is generally minor in adult animals [69-71], and enterohepatic recirculation of BPA, which occurs to a minor extent in rodents and even less in primates [72, 73]. Importantly, a side-byside analysis of serum BPA concentrations in mice and rhesus monkeys (Macaca mulatta), who were both given a comparable oral bolus, demonstrated that the clearance of BPA was comparable in the two species [73]. Thus, even though there are minor differences in the pharmacokinetics of BPA metabolism between rodents and primates, findings in rodents are almost assuredly applicable to primates, including humans [73-75].

While BPA weakly binds to ESR1 and ESR2, it is not clear if all of the above sex-specific behavioral differences are due to engaging these steroid receptors. This chemical can also bind to other steroid and non-steroid receptors, such as thyroxine receptor (TR), AR, glucocorticoid receptor (GR), peroxisome proliferator-activated receptor (PPAR ), and pregnane $\mathrm{X}$ receptor $[43,76-79]$.

\section{Other Endocrine-Disrupting Compounds}

It is beyond the scope of this review to cover all of the EDCs that are proposed to disrupt sexually dimorphic behaviors in various animal models. Table 2 provides a comprehensive list of other EDCs and their impact on the above behavioral categories. Three types of examples are (1) the estrogenic compounds EE, estrogen present in birth control pills, and diethylstilbestrol (DES), which was administered from the 1950 s to the 1970s under the misconception that it prevented miscarriages; (2) the androgenic compounds testosterone, $17 \alpha$ methyldihydrotestosterone (MDHT), and levonorgestrel, and the antiandrogenic class, exemplified by flutamide; and (3) a broad range of other EDCs, including insecticides, such as methoxychlor (MXC) and dichlorodiphenyltrichloroethane (DDT) and its active metabolite, dichlorodiphenyldichloroethylene (p,p-DDE), fungicides (especially vinclozolin, which has antiandrogenic properties), plasticizers [e.g., di(2-ethylhexyl) phthalate (DEHP)], and coolants/insulating fluids (e.g., polychlorinated biphenyls [PCBs]). Even some commonly used antimicrobials, such as triclosan and triclobarban, may exert endocrine disrupting properties. The two illustrative chemicals, EE and vinclozolin, where across taxa sex-specific disruptions have been reported, will be further discussed.

Effects of EE on sex-specific behaviors have been documented in a wide range of species, including rodents, fish, pipefish, frogs, and birds, as detailed above (for Peromyscus species, where BPA was tested alongside $\mathrm{EE}$, as required by current FDA guidelines for BPA studies) and below. Sand goby (Pomatoschistus minutus) males exposed to EE as adults become demasculinized, as evidenced by their protracted time to engage in nest-building, compromised courtship behaviors, diminished aggressive behaviors, and altered parental care relative to control males [80, 81]. Gulf pipefish (Syngnathus scovelli) possess sex-role reversal in that females must compete for a limited number of males to carry fertilized eggs. However, EE-treated males exhibited femalelike secondary sexual traits, and mate choice trials have revealed that females, which are typically not the choosier sex in this species, selectively reject these males [82]. African clawed male frogs exposed as adults to EE display reductions in the number of and temporal/spectral qualities in advertisement calls and demonstrate elevated number of rasping calls [83]. Moreover, females selectively reject these males in mate choice trials. In ovo exposure of Japanese quail (Coturnix japonica) to EE leads to later depression of male sexual behaviors [84]. Taken together, the cross-species findings provide robust evidence that developmental and adult exposure to EE compromises later male sexual behaviors and attractiveness to females across taxa.

The antiandrogenic compound vinclozolin has been reported to disrupt sexually dimorphic behaviors in fish, frogs, and 


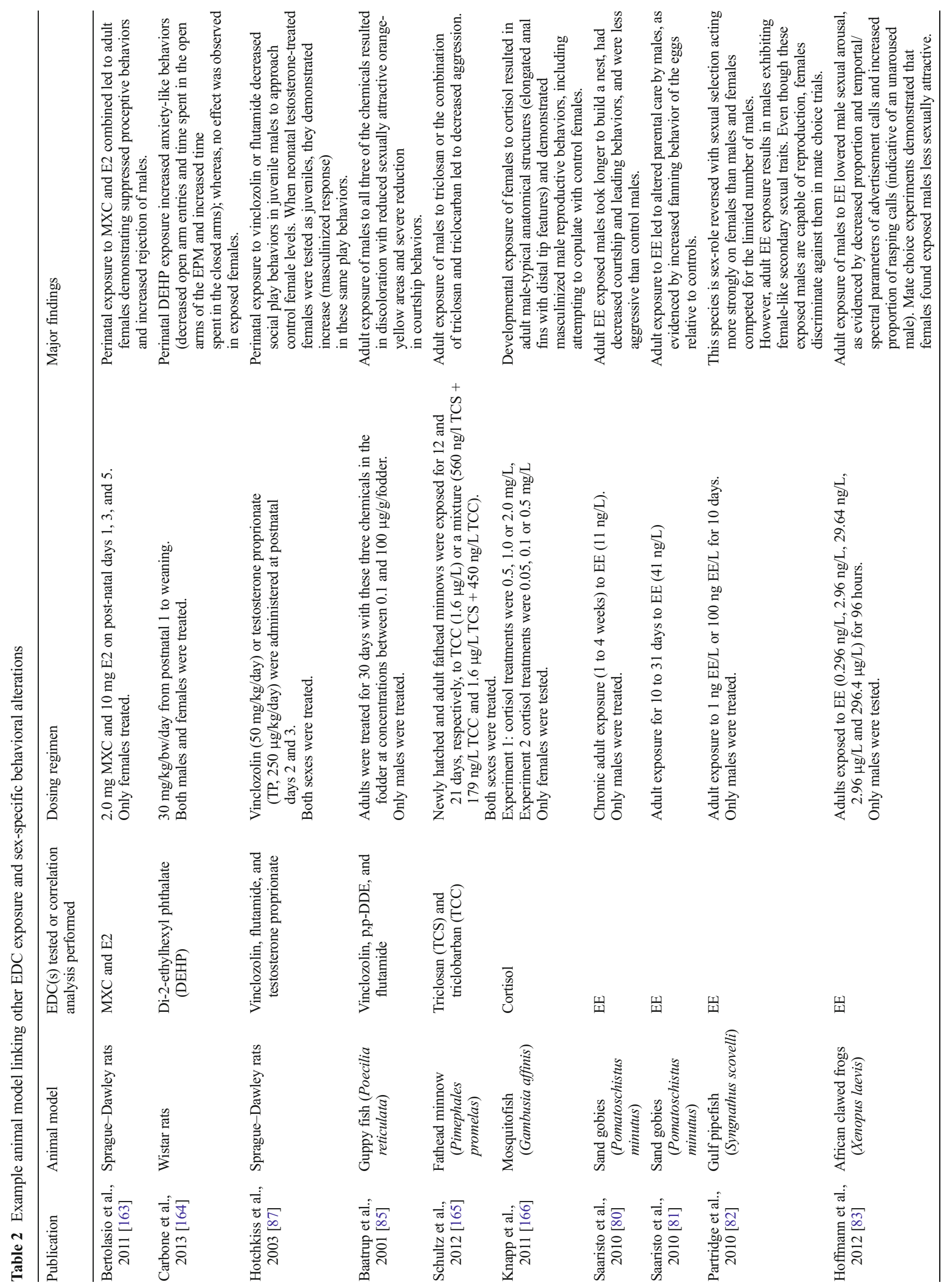


rodents. In guppy fish (Poecilia reticulata), males exposed as adults to this chemical possessed less sexually attractive orange-yellow coloration and suppression of male-typical courtship behaviors [85]. Male African clawed frogs (Xenopus laevis) exposed as adults to vinclozolin demonstrated a decreased proportion of advertisement calls and chirping (indicative of an aroused state) and an increased proportion of rasping calls (indicative of a non-aroused state) [86]. Perinatal exposure to vinclozolin or flutamide eliminates male-typical social play behaviors in Sprague Dawley juvenile male rats [87].

\section{Sexually Dimorphic Behavioral Differences in Psychosocial Stress}

Just as the effects of EDC depend on developmental timing, the effects of psychosocial stress on the brain and behavior also depend on the stage of development. Intriguingly, when the mother is exposed to psychosocial stress during pregnancy, stronger effects are observed in male offspring, whereas the effects of psychosocial stress during adolescence or after sexual maturity are usually stronger in females.

\section{Early Life Stress}

Early life stress induces long-lasting changes in a diverse set of metabolic and neurobiological systems [88]. The effects of psychosocial stress early during gestation usually have more long-lasting consequences than the effects of stress later in gestation. For example, when pregnant female mice were exposed to chronic variable stress, male but not female offspring spent more time floating in the forced swim test [89]. Floating in this test is considered to be a measure of behavioral despair because drugs with antidepressant properties reduce floating and increase swimming [90]. Although many physiological systems are affected by psychosocial stress, the impact of elevated glucocorticoids has been best studied. When rat dams were injected with corticosterone during pregnancy, male but not female adolescent offspring showed increased anxiety-like behavior [91]. Corticosterone injections during pregnancy also increased floating behavior in the forced swim test in both male and female adolescent offspring. On average, it appears that males are more sensitive to glucocorticoids during prenatal development, which is consistent with the findings from clinical studies reporting that maternal depression during or after pregnancy has stronger effects on anxiety in boys than in girls [92]

Increased corticosterone levels in the mother can also impact postnatal development. Dams injected with corticosterone have increased corticosterone levels in breast milk, as well as increased brain levels of corticosterone in their pups [93]. Males but not females had suppressed neurogenesis in 
the hippocampus [94], which is thought to be an important mechanism conferring resilience to the long-term effects of stress [95]. In this study, postnatal corticosterone exposure had no effects on behavior in the forced swim test, which is a short-term behavioral response. Future studies could also consider the impact of postnatal corticosterone exposure on longer-lasting stressors, such as chronic variable stress or social defeat.

Adolescence appears to be an important transition with regard to sex differences in sensitivity to psychosocial stress [96]. In adolescent rats, a combination of social and physical stressors increased depression-like behaviors in females but not in males [97•]. Adolescent stress also increases behavioral sensitivity to drugs of abuse, and this effect is stronger in female rats than in males [98]. These results suggest that females have increased physiological responses to psychosocial stress during adolescence. These findings are also consistent with epidemiological work supporting the hypothesis that girls are more likely than boys to carry risk factors for stressinduced mental disorders (such as depression), and that the challenges of adolescence engage these risk factors to impact mental health $[99,100]$.

\section{Chronic Mild Stress}

The chronic mild stress (CMS) paradigm has become a widely used approach to induce behavioral phenotypes associated with depression. CMS consists of a combination of physical and low-level social stressors administered in an unpredictable order [101]. Examples of stressors include changes of cage mates, exposure to cold temperatures, and disruption of light cycles. One of the most common responses to CMS is anhedonia, or reduced interest in rewards, such as sucrose, high-fat food, or sex. Reduced motivation to obtain reward is a key component of depression [102]. Consumption of preferred food items, such as sucrose, generates hedonic behavioral responses, which are evolutionarily conserved [103]. There have been concerns that reduced sucrose intake could be induced by stress-induced weight loss rather than by anhedonia per se [104]. While stress-induced weight loss can be included as a covariate statistically [105], some laboratories have been unable to replicate the effects of CMS on sucrose intake [106, 107]. An intriguing alternative approach is examination of more ethological measures of behavior. For example, several lab groups have observed that CMS reduces male sexual behavior in rats [108-110]. Although more study is needed, it will be interesting to see if the effects of CMS on sexual behavior are more robust than the effects on food/taste preferences.

The overwhelming majority of CMS studies have focused on males, but a few have examined females [111]. In general, CMS reduced sucrose consumption in both males and females. While stress-induced anhedonia is usually stronger in females [112-114], some studies have reported that males and females are equally affected $[115,116]$. This inconsistency suggests that the use of more ethological approaches, such as sexual behavior, could be useful. The effect of social isolation on anhedonia has also been reported to induce stronger responses in females [117]. However when male and female rats were challenged with a novel stressor (the forced swim test), females exposed to CMS engaged in more floating behavior (considered to be an index of behavioral despair), whereas males engaged in less floating behavior [112]. To our knowledge, no study has examined whether CMS impairs female sexual behavior. Mixed results have been reported on the effects on CMS on the hypothalamic-pituitary-adrenal (HPA) axis. The most common result is that CMS increases baseline corticosterone levels, which has been reported in both males [107, 112, 118, 119] and females [114]. However, other reports have noted no effects of CMS on corticosterone levels [116, 120-122]. Divergent results may be a result of genetic variability across genetic lines. There is substantial variation in coping responses between the different lines of rats [123]. Some lines respond to stress with reactive coping strategies, consisting of behavioral responses such as immobility. Other lines respond with more proactive coping strategies, such as escape. Individuals using more reactive coping strategies are more likely to have higher stress-induced glucocorticoid levels than individuals using more proactive strategies [124].

\section{Social Stress}

A powerful source of stress in many species comes from competitive interactions and aggression. Interestingly, many of the behavioral and neurobiological phenotypes observed in individuals that lose aggressive encounters are evolutionarily conserved $[125,126]$. One of the most widely reported phenotypes induced by defeat stress is withdrawal from social contexts, even non-threatening contexts [127, 128]. Social withdrawal has special relevance for mental health, because patients diagnosed with depression show stronger avoidance responses to social cues $[129,130]$. Social avoidance further reduces social support and helps to maintain depression [131]. Like CMS, defeat stress induces reduced intake of sucrose $[132,133]$. Scent marking can also be used to estimate sexual motivation, and this behavior is strongly inhibited by defeat stress [134]. Defeat stress has proven to be a robust approach, as many behavioral phenotypes have been replicated in different lab groups and species [125]. One drawback, however, is that it has been very difficult to study sex differences, because female rats and mice are generally not aggressive toward other females. However, creative use of different species or manipulations of context have allowed several groups to study defeat stress in females.

Under certain conditions, lactating female rats will engage in aggression toward other females. Variability between 
different rat strains may be an important factor influencing the intensity of defeat. Sprague Dawley dams appear to have lower aggression levels, and females exposed to defeat by a dam actually had decreased levels of floating behavior in the forced swim test, compared with controls [135]. In contrast, Wistar dams appear to have higher aggression levels, and females exposed to defeat showed increased floating in the forced swim test and sucrose anhedonia [136]. Long-Evans dams also appear to be more aggressive, and females exposed to defeat showed increases in depression-like behaviors [137•] and increased selfadministration of cocaine [138]. This approach represents a significant advance because it allows for the study of defeat stress in a species in which there is a strong literature in males. However, given the relatively low aggression levels of dams toward other females, it is harder to directly compare males and females. Other rodent species such as Syrian hamsters (Mesocricetus auratus) and California mice (Peromyscus californicus) allow for more direct comparisons of males and females because their intrafemale aggression levels are higher and females will engage in aggression in the absence of pups. Intriguingly, female Syrian hamsters appear to be more resistant to the behavioral effects of defeat stress than males [139], and this resistance appears to be mediated in part by circulating estradiol [140]. In California mice, defeat stress has very different longterm effects on behavior and the HPA axis in males and females.

The California mouse is a monogamous species, in which both males and females defend a territory. Female California mice are aggressive in resident-intruder tests [141], which facilitates the use of social defeat in both males and females. Acute responses of the HPA axis are more sensitive to social conflict in females than in males. Females show a significant increase in corticosterone following a resident-intruder test, and this increase is observed in both residents (winners [142]) and intruders (losers [143]). In contrast, neither male residents nor intruders show an increase in corticosterone. This sex difference in corticosterone responsiveness is mediated by gonadal hormones (Fig. 1a). Castration sensitizes male corticosterone responses to defeat stress, whereas ovariectomy blocks defeat-induced increases in corticosterone in females [143]. Notably, the long-term effects of defeat stress on baseline corticosterone are quite different. Defeat stress increases male baseline corticosterone during both the active phase and the inactive phase, but has no effect on females [144••], which is similar to findings in female rats [135]. Elevated corticosterone during the inactive phase is often observed in patients diagnosed with depression, and some recent reports have suggested that this symptom is more likely to occur in men $[145,146]$. While defeat stress has a stronger effect on baseline corticosterone levels in males, defeat stress has a stronger effect on social interaction behavior in female California mice.

Male and female California mice are highly motivated to approach unfamiliar individuals, like many other strains of Mus [147]. However, social defeat reliably reduces social
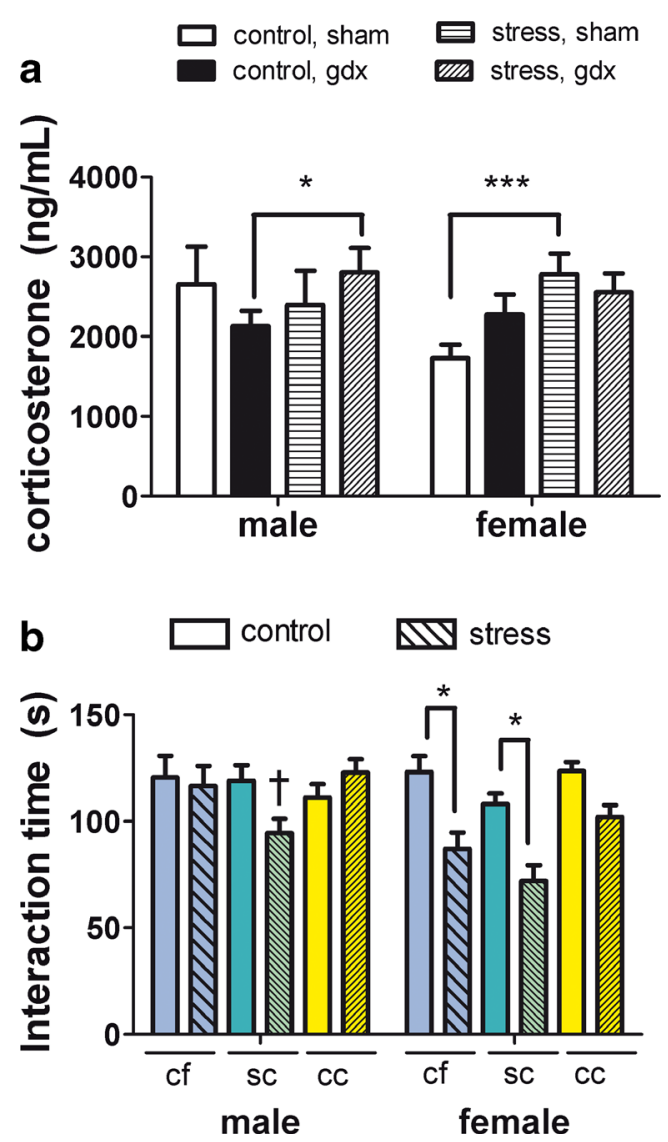

Fig. 1 Effects of social defeat on corticosterone (a) and social interaction (b) behavior in California mice. Social stress increases corticosterone levels in female California mice, and ovariectomy blocks this effect. In contrast, castrated males have increased corticosterone levels following stress. The effect of defeat stress on social interaction is stronger in females than in males, but the effect is weaker in females raised on corncob bedding. $* p<0.05$ versus control, $* * * p<0.001$ versus control, $\dagger p<0.05$ male versus female. $c c$ corncob, $c f$ cardboard bedding, $G d x$ gonadectomy, $s c$ woodchip bedding

approach in female California mice, whereas this effect is weaker or absent in male California mice [144••, 148]. This result mimics reports in humans that social withdrawal occurs to a greater degree in women with depression than in men [149]. Unlike the effects of defeat stress on corticosterone, there is no effect of gonadectomy on social interaction behavior [143]. Similarly, social withdrawal is observed across different stages of the estrous cycle [144••]. These results suggest a diminished role for gonadal hormones in mediating sex differences in social withdrawal behavior in adults. However, there is evidence that hormones may have more important effects early in life. This evidence comes from an unexpected finding that cage bedding has important effects on behavioral responses to stress (Fig. 1b). Corncob bedding contains tetrahydrofuran (THF) diols, which have estrogenic properties but do not bind directly to ESRs [150]. California mice raised on corncob have significantly elevated levels of THF diols [151], most likely through consumption of 
bedding. When female California mice were raised on corncob bedding, the effect of defeat stress on social interaction behavior was blunted, compared with females raised on aspen wood chips or cardboard-based bedding [143]. This finding suggests that females raised on corncob could be masculinized during development. Interestingly, THF diols stimulate cyclooxygenase (COX)-2 activity [152]. In male rats, estradiol increases COX2 activity to increase production of prostaglandins in the preoptic area (POA) of the hypothalamus [153]. Prostaglandins induce the formation of dendritic spines in the POA, which are more abundant in males than in females and are thought to play an important role in controlling male sexual behavior [154].

\section{Conclusions}

Developmental/adult exposure to EDCs - in particular, BPA - is associated with sex-specific effects in various animal models and human epidemiological studies. Across animal models, male sexually selected traits that affect intrasexual competition and intersexual choice appear to be especially vulnerable to the EDCs that have been tested to date. EDCs also seem to exert sex-specific effects on anxiety/depressivelike behaviors in animal models and human epidemiological studies [24••, 39, 49, 58-60, 63-65]. While only a handful of studies have directly assessed linkages between BPA exposure and sex-specific behavioral differences in humans, a somewhat consistent finding is that prenatal BPA exposure is linked to increased externalizing behavioral problems, particularly in older boys [63-65]. However, future studies are needed to clarify whether early BPA exposure alters neurobehavioral programming in animal models and humans, and whether the observed differences persist with maturity.

EDCs likely exert sex-specific behavioral effects by disrupting normal steroid programming of the brain, which could occur through direct binding of neural steroid receptors [155-157], modulation of steroid hormone synthesis or metabolism [156-158], and/or epigenetic alterations of steroiddependent genes [159]. These changes likely shape how an individual reacts to challenges faced later in life.

The effects of psychosocial stress are also dependent on the developmental stage, with males exhibiting increased vulnerability during the prenatal stage and females exhibiting increased sensitivity in adolescence. In adults, the effects of psychosocial stress are sex dependent. For example, defeat stress induces social withdrawal in females and disrupts baseline corticosterone levels in males.

Future studies should thus consider the combined impact of early exposure to an EDC, such as BPA, and later life stress (the "two-hit" model) on sex-specific behaviors. It is clear that BPA can induce anxiogenic effects, which vary according to the sex.
However, the interaction between BPA exposure and psychosocial stress is still unclear. It will be essential to disentangle direct effects of BPA on brain development from indirect effects of BPA that may be mediated by altered parental behavior. BPA reduces hypothalamic GR expression [160], which might exaggerate glucocorticoid responses to stress. It has also been suggested that BPA can directly bind and activate GR [77], which would be another avenue by which BPA can affect later social and environmental stressors [161].

In conclusion, behaviors such as sexually selected traits might serve as a barometer of exposure to EDC or psychosocial stress. An important implication of sex-specific disruptions in behavior is the long-term impact on susceptibility to stress later in life. There are important sex differences in behavioral and neurobiological responses to stress [125, 162], and at least some of these differences originate from early life experience. Thus exposure to EDC early in life is likely to alter sex-specific responses to stress in adults. However, to our knowledge, there has been no study to date aimed at testing this novel hypothesis that developmental exposure to EDCs followed by later social/environmental stressors can lead to harmful biomolecular and behavioral changes that are sex dependent. Therefore, future studies are needed to determine the potential combined epigenetic and gene expression effects that these extrinsic factors exert on the various brain regions governing adult cognitive and sociosexual behaviors and whether the neurobehavioral responses vary according to sex.

Acknowledgments Drs. Sandra M. Losa-Ward, Heather B. Patisaul, and Joseph M. Braun are acknowledged for identifying some of the articles that report sex differences in response to BPA.

Cheryl S. Rosenfeld's support includes grant nos. RC1 1026 ES018195 and U01 ES020929, a Mizzou Advantage Grant, and a University of Missouri College of Veterinary Medicine Faculty Award. Brian C. Trainor is supported by grant nos. R01 MH085069 and R01 MH097714.

\section{Compliance with Ethics Guidelines}

Conflict of Interest Cheryl S. Rosenfeld and Brian C. Trainor declare that they have no conflict of interest.

Human and Animal Rights and Informed Consent This article does not contain any studies with human or animal subjects performed by any of the authors.

\section{References}

Papers of particular interest, published recently, have been highlighted as:

- Of importance

-. Of major importance

1. Rosenfeld CS. Effects of maternal diet and exposure to bisphenol A on sexually dimorphic responses in conceptuses and offspring. Reprod Domest Anim. 2012;47 Suppl 4:23-30. 
2. Hanson M, Gluckman P. Developmental origins of noncommunicable disease: population and public health implications. Am J Clin Nutr. 2011;94:1754S-8.

3. Barker DJ. Maternal nutrition, fetal nutrition, and disease in later life. Nutrition. 1997;13:807-13.

4. Barouki R, Gluckman PD, Grandjean P, Hanson M, Heindel JJ. Developmental origins of non-communicable disease: implications for research and public health. Environ Health. 2012;11:42. This article synthesizes the current understanding of developmental origins of health and disease for a range of systems, implications for public health policy, and evidence that prevention strategies to prevent later adverse health outcomes should focus on the perinatal period.

5. Arnold AP, Breedlove SM. Organizational and activational effects of sex steroids on brain and behavior: a reanalysis. Horm Behav. 1985;19:469-98.

6. Morris JA, Jordan CL, Breedlove SM. Sexual differentiation of the vertebrate nervous system. Nat Neurosci. 2004;7:1034-9.

7. McCarthy MM. Estradiol and the developing brain. Physiol Rev. 2008;88:91-124.

8. Phoenix CH, Goy RW, Gerall AA, Young WC. Organizing action of prenatally administered testosterone propionate on the tissues mediating mating behavior in the female guinea pig. Endocrinology. 1959;65:369-82.

9. Robinson J. Prenatal programming of the female reproductive neuroendocrine system by androgens. Reproduction. 2006;132: $539-47$

10. Scott HM, Mason JI, Sharpe RM. Steroidogenesis in the fetal testis and its susceptibility to disruption by exogenous compounds. Endocr Rev. 2009;30:883-925.

11. Nugent BM, Tobet SA, Lara HE, Lucion AB, Wilson ME, Recabarren SE, et al. Hormonal programming across the lifespan. Horm Metab Res. 2012;44:577-86.

12. O'Donnell K, O'Connor TG, Glover V. Prenatal stress and neurodevelopment of the child: focus on the HPA axis and role of the placenta. Dev Neurosci. 2009;31:285-92.

13. McCarthy MM, Arnold AP. Reframing sexual differentiation of the brain. Nat Neurosci. 2011;14:677-83. This article summarizes the current understanding of how environmental factors, gonadal steroid hormones, and molecular signals and pathways interact to govern sex differences in brain development.

14. Mao J, Zhang X, Sieli PT, Falduto MT, Torres KE, Rosenfeld CS. Contrasting effects of different maternal diets on sexually dimorphic gene expression in the murine placenta. Proc Natl Acad Sci U S A. 2010;107:5557-62.

15. Mueller BR, Bale TL. Sex-specific programming of offspring emotionality after stress early in pregnancy. J Neurosci. 2008;28: 9055-65.

16. Gabory A, Ferry L, Fajardy I, Jouneau L, Gothie JD, Vige A, et al. Maternal diets trigger sex-specific divergent trajectories of gene expression and epigenetic systems in mouse placenta. PLoS One. 2012; 7:e47986

17. Hard GC, Whysner J. Risk assessment of d-limonene: an example of male rat-specific renal tumorigens. Crit Rev Toxicol. 1994;24: 231-54.

18. Blumbach K, Pahler A, Deger HM, Dekant W. Biotransformation and male rat-specific renal toxicity of diethyl ethyl- and dimethyl methylphosphonate. Toxicol Sci. 2000;53:24-32.

19. Jasarevic E, Geary D, Rosenfeld C. Sexually selected traits: a fundamental framework for studies on behavioral epigenetics. ILAR J. 2012;53:253-69.

20. Darwin C. The descent of man, and selection in relation to sex. London: John Murray; 1871.

21. Trivers RL. Parental investment and sexual selection. In: Campbell B, editor. Sexual selection and the descent of man, 1871-1971. Chicago: Aldine; 1972. p. 136-79.
22. Edward DA, Chapman T. The evolution and significance of male mate choice. Trends Ecol Evol. 2011;26:647-54.

23. Trainor BC, Marler CA. Testosterone, paternal behavior, and aggression in the monogamous California mouse (Peromyscus californicus). Horm Behav. 2001;40:32-42.

24.• Jasarevic E, Sieli PT, Twellman EE, Welsh Jr TH, Schachtman TR, Roberts RM, et al. Disruption of adult expression of sexually selected traits by developmental exposure to bisphenol A. Proc Natl Acad Sci U S A. 2011;108:11715-20. This article was one of the first to establish that sexually selected traits are vulnerable to developmental exposure to the endocrine-disrupting compounds bisphenol $A$ and ethinyl estradiol, and that females will discriminate against males that have been developmentally exposed to $B P A$.

25. León-Olea M, Martyniuk CJ, Orlando EF, Ottinger MA, Rosenfeld CS, Wolstenholme JT, et al. Current concepts in neuroendocrine disruption. Gen Comp Endocrinol. 2014;203C:158 73.

26. Jasarevic E, Geary DC, Rosenfeld CS. Sexually selected traits: a fundamental framework for studies on behavioral epigenetics. ILAR J. 2012;53:253-69.

27. Bowers JM, Waddell J, McCarthy MM. A developmental sex difference in hippocampal neurogenesis is mediated by endogenous oestradiol. Biol Sex Differ. 2010;1:8.

28. Konkle AT, McCarthy MM. Developmental time course of estradiol, testosterone, and dihydrotestosterone levels in discrete regions of male and female rat brain. Endocrinology. 2011;152:223-35.

29. Watson J, Adkins-Regan E. Activation of sexual behavior by implantation of testosterone propionate and estradiol benzoate into the preoptic area of the male Japanese quail (Coturnix japonica). Horm Behav. 1989;23:251-68.

30. Watson J, Adkins-Regan E. Testosterone implanted in the preoptic area of male Japanese quail must be aromatized to activate copulation. Horm Behav. 1989;23:432-47.

31. Mitterling KL, Spencer JL, Dziedzic N, Shenoy S, McCarthy K, Waters EM, et al. Cellular and subcellular localization of estrogen and progestin receptor immunoreactivities in the mouse hippocampus. J Comp Neurol. 2010;518:2729-43.

32. Zuloaga DG, Zuloaga KL, Hinds LR, Carbone DL, Handa RJ. Estrogen receptor beta expression in the mouse forebrain: age and sex differences. J Comp Neurol. 2014;522:358-71.

33. Cao J, Patisaul HB. Sexually dimorphic expression of hypothalamic estrogen receptors alpha and beta and Kiss1 in neonatal male and female rats. J Comp Neurol. 2011;519:2954-77.

34. Ikeda Y, Nagai A, Ikeda MA, Hayashi S. Sexually dimorphic and estrogen-dependent expression of estrogen receptor beta in the ventromedial hypothalamus during rat postnatal development. Endocrinology. 2003;144:5098-104.

35. McEwen BS. Invited review: estrogens effects on the brain. Multiple sites and molecular mechanisms. J Appl Physiol. (1985) 2001;91:2785-2801.

36. Walker DM, Kirson D, Perez LF, Gore AC. Molecular profiling of postnatal development of the hypothalamus in female and male rats. Biol Reprod. 2012;87:129.

37. Kumar RC, Thakur MK. Androgen receptor mRNA is inversely regulated by testosterone and estradiol in adult mouse brain. Neurobiol Aging. 2004;25:925-33.

38. Kurian JR, Olesen KM, Auger AP. Sex differences in epigenetic regulation of the estrogen receptor-alpha promoter within the developing preoptic area. Endocrinology. 2010;151:2297305.

39. Kundakovic M, Gudsnuk K, Franks B, Madrid J, Miller RL, Perera FP, et al. Sex-specific epigenetic disruption and behavioral changes following low-dose in utero bisphenol A exposure. Proc Natl Acad Sci U S A. 2013;110(24):9956-61. 
40. Cao J, Rebuli ME, Rogers J, Todd KL, Leyrer SM, Ferguson SA, et al. Prenatal bisphenol A exposure alters sex-specific estrogen receptor expression in the neonatal rat hypothalamus and amygdala. Toxicol Sci. 2013;133:157-73.

41. Diamanti-Kandarakis E, Bourguignon JP, Giudice LC, Hauser R, Prins GS, Soto AM, et al. Endocrine-disrupting chemicals: an Endocrine Society scientific statement. Endocr Rev. 2009;30:293342.

42. Environment Canada, Health Canada (2008). Screening assessment for the challenge: phenol, 4,4'-(1-methylethylidene)bis-(bisphenol A). Chemical Abstracts Service Registry Number 80-05-7. http://www. ec.gc.ca/ese-ees/3C756383-BEB3-45D5-B8D3-E8C800F35243/ batch2 80-05-7 en.pdf. Accessed 30 Aug 2014.

43. Vandenberg LN, Maffini MV, Sonnenschein C, Rubin BS, Soto AM. Bisphenol-A and the great divide: a review of controversies in the field of endocrine disruption. Endocr Rev. 2009;30:75-95.

44. Calafat AM, Ye X, Wong LY, Reidy JA, Needham LL. Exposure of the US population to bisphenol A and 4-tertiary-octylphenol: 2003-2004. Environ Health Perspect. 2008;116:39-44.

45. vom Saal FS, Akingbemi BT, Belcher SM, Birnbaum LS, Crain DA, Eriksen M, et al. Chapel Hill Bisphenol A Expert Panel consensus statement: integration of mechanisms, effects in animals and potential to impact human health at current levels of exposure. Reprod Toxicol. 2007;24:131-8.

46. Vandenberg LN, Hauser R, Marcus M, Olea N, Welshons WV. Human exposure to bisphenol A (BPA). Reprod Toxicol. 2007;24: 139-77.

47. Galea LA, Kavaliers M, Ossenkopp KP. Sexually dimorphic spatial learning in meadow voles Microtus pennsylvanicus and deer mice Peromyscus maniculatus. J Exp Biol. 1996;199:195-200.

48. Pyter LM, Trainor BC, Nelson RJ. Testosterone and photoperiod interact to affect spatial learning and memory in adult male whitefooted mice (Peromyscus leucopus). Eur J Neurosci. 2006;23: 3056-62.

49. Jasarevic E, Williams SA, Vandas GM, Ellersieck MR, Liao C, Kannan K, et al. Sex and dose-dependent effects of developmental exposure to bisphenol A on anxiety and spatial learning in deer mice (Peromyscus maniculatus bairdii) offspring. Horm Behav. 2013;63:180-9.

50. Xu X, Liu X, Zhang Q, Zhang G, Lu Y, Ruan Q, et al. Sex-specific effects of bisphenol-A on memory and synaptic structural modification in hippocampus of adult mice. Horm Behav. 2013;63: 766-75.

51. Shughrue PJ, Merchenthaler I. Estrogen is more than just a "sex hormone": novel sites for estrogen action in the hippocampus and cerebral cortex. Front Neuroendocrinol. 2000;21:95-101.

52. Pan M, Zhang C. Stimulatory effect of gonadal hormones on fetal rat hippocampal neural proliferation requires neurotrophin receptor activation in vitro. Neurosci Lett. 2013;546:1-5.

53. Galea LA, Uban KA, Epp JR, Brummelte S, Barha CK, Wilson WL, et al. Endocrine regulation of cognition and neuroplasticity: our pursuit to unveil the complex interaction between hormones, the brain, and behaviour. Can J Exp Psychol. 2008;62:24760 .

54. Jasarevic E, Williams SA, Roberts RM, Geary DC, Rosenfeld CS. Spatial navigation strategies in Peromyscus: a comparative study. Anim Behav. 2012;84:1141-9.

55. Williams SA, Jasarevic E, Vandas GM, Warzak DA, Geary DC, Ellersieck MR, et al. Effects of developmental bisphenol A exposure on reproductive-related behaviors in California mice (Peromyscus californicus): a monogamous animal model. PLoS One. 2013;8:e55698

56. Ryan BC, Hotchkiss AK, Crofton KM, Gray Jr LE. In utero and lactational exposure to bisphenol A, in contrast to ethinyl estradiol, does not alter sexually dimorphic behavior, puberty, fertility, and anatomy of female LE rats. Toxicol Sci. 2010;114:133-48.
57. Ryan BC, Vandenbergh JG. Developmental exposure to environmental estrogens alters anxiety and spatial memory in female mice. Horm Behav. 2006;50:85-93.

58. Cox KH, Gatewood JD, Howeth C, Rissman EF. Gestational exposure to bisphenol $\mathrm{A}$ and cross-fostering affect behaviors in juvenile mice. Horm Behav. 2010;58:754-61.

59. Xu X, Hong X, Xie L, Li T, Yang Y, Zhang Q, et al. Gestational and lactational exposure to bisphenol-A affects anxiety- and depression-like behaviors in mice. Horm Behav. 2012;62:480-90.

60. Gioiosa L, Parmigiani S, Vom Saal FS, Palanza P. The effects of bisphenol A on emotional behavior depend upon the timing of exposure, age and gender in mice. Horm Behav. 2013;63:598605.

61. Kundakovic M, Gudsnuk K, Franks B, Madrid J, Miller RL, Perera FP, et al. Sex-specific epigenetic disruption and behavioral changes following low-dose in utero bisphenol A exposure. Proc Natl Acad Sci U S A. 2013;110:9956-61.

62. Jones BA, Watson NV. Perinatal BPA exposure demasculinizes males in measures of affect but has no effect on water maze learning in adulthood. Horm Behav. 2012;61:605-10.

63. Braun JM, Yolton K, Dietrich KN, Hornung R, Ye X, Calafat AM, et al. Prenatal bisphenol A exposure and early childhood behavior. Environ Health Perspect. 2009;117:1945-52.

64. Perera F, Vishnevetsky J, Herbstman JB, Calafat AM, Xiong W, Rauh V, et al. Prenatal bisphenol A exposure and child behavior in an inner-city cohort. Environ Health Perspect. 2012;120:1190 4.

65. Harley KG, Gunier RB, Kogut K, Johnson C, Bradman A, Calafat $\mathrm{AM}$, et al. Prenatal and early childhood bisphenol A concentrations and behavior in school-aged children. Environ Res. 2013; 126:43-50.

66. Egger HL, Angold A. Common emotional and behavioral disorders in preschool children: presentation, nosology, and epidemiology. J Child Psychol Psychiatry. 2006;47:313-37.

67. Inoue H, Tsuruta A, Kudo S, Ishii T, Fukushima Y, Iwano H, et al. Bisphenol a glucuronidation and excretion in liver of pregnant and nonpregnant female rats. Drug Metab Dispos. 2005;33:55-9.

68. Sakamoto T, Eguchi H, Omoto Y, Ayabe T, Mori H, Hayashi S. Estrogen receptor-mediated effects of tamoxifen on human endometrial cancer cells. Mol Cell Endocrinol. 2002;192:93-104.

69. Balakrishnan B, Henare K, Thorstensen EB, Ponnampalam AP, Mitchell MD. Transfer of bisphenol A across the human placenta. Am J Obstet Gynecol. 2010;202:393 e391-397.

70. Kurebayashi H, Betsui H, Ohno Y. Disposition of a low dose of 14C-bisphenol $\mathrm{A}$ in male rats and its main biliary excretion as BPA glucuronide. Toxicol Sci. 2003;73:17-25.

71. Pottenger LH, Domoradzki JY, Markham DA, Hansen SC, Cagen SZ, Waechter JM. The relative bioavailability and metabolism of bisphenol $\mathrm{A}$ in rats is dependent upon the route of administration. Toxicol Sci. 2000;54:3-18.

72. Doerge DR, Twaddle NC, Vanlandingham M, Fisher JW. Pharmacokinetics of bisphenol $\mathrm{A}$ in neonatal and adult Sprague-Dawley rats. Toxicol Appl Pharmacol. 2010;247:15865.

73. Taylor JA, Vom Saal FS, Welshons WV, Drury B, Rottinghaus G, Hunt PA, et al. Similarity of bisphenol A pharmacokinetics in rhesus monkeys and mice: relevance for human exposure. Environ Health Perspect. 2011;119:422-30.

74. Gies A, Heinzow B, Dieter HH, Heindel J. Bisphenol A Workshop of the German Federal Environment Agency-March 30-31, 2009 Work Group report: public health issues of bisphenol A. Int J Hyg Environ Health. 2009;212:693-6.

75. Sieli PT, Jasarevic E, Warzak DA, Mao J, Ellersieck MR, Liao C, et al. Comparison of serum bisphenol A concentrations in mice exposed to bisphenol A through the diet versus oral bolus exposure. Environ Health Perspect. 2011;119:1260-5. 
76. Alonso-Magdalena P, Ropero AB, Soriano S, Garcia-Arevalo M, Ripoll C, Fuentes E, et al. Bisphenol-A acts as a potent estrogen via non-classical estrogen triggered pathways. Mol Cell Endocrinol. 2012;355:201-7.

77. Prasanth GK, Divya LM, Sadasivan C. Bisphenol-A can bind to human glucocorticoid receptor as an agonist: an in silico study. J Appl Toxicol. 2010;30:769-74.

78. Riu A, Grimaldi M, le Maire A, Bey G, Phillips K, Boulahtouf A, et al. Peroxisome proliferator-activated receptor gamma is a target for halogenated analogs of bisphenol A. Environ Health Perspect. 2011;119:1227-32.

79. Sui Y, Ai N, Park SH, Rios-Pilier J, Perkins JT, Welsh WJ, et al. Bisphenol A and its analogues activate human pregnane $\mathrm{X}$ receptor. Environ Health Perspect. 2012;120:399-405.

80. Saaristo M, Craft JA, Lehtonen KK, Lindstrom K. Exposure to 17alpha-ethinyl estradiol impairs courtship and aggressive behaviour of male sand gobies (Pomatoschistus minutus). Chemosphere. 2010;79:541-6.

81. Saaristo M, Craft JA, Lehtonen KK, Lindstrom K. An endocrine disrupting chemical changes courtship and parental care in the sand goby. Aquat Toxicol. 2010;97:285-92.

82. Partridge C, Boettcher A, Jones AG. Short-term exposure to a synthetic estrogen disrupts mating dynamics in a pipefish. Horm Behav. 2010;58:800-7.

83. Hoffmann F, Kloas W. Estrogens can disrupt amphibian mating behavior. PLoS One. 2012;7:e32097.

84. Halldin K, Berg C, Brandt I, Brunstrom B. Sexual behavior in Japanese quail as a test end point for endocrine disruption: effects of in ovo exposure to ethinylestradiol and diethylstilbestrol. Environ Health Perspect. 1999;107:861-6.

85. Baatrup E, Junge M. Antiandrogenic pesticides disrupt sexual characteristics in the adult male guppy Poecilia reticulata. Environ Health Perspect. 2001;109:1063-70.

86. Hoffmann F, Kloas W. An environmentally relevant endocrinedisrupting antiandrogen, vinclozolin, affects calling behavior of male Xenopus laevis. Horm Behav. 2010;58:653-9.

87. Hotchkiss AK, Ostby JS, Vandenbergh JG, Gray Jr LE. An environmental antiandrogen, vinclozolin, alters the organization of play behavior. Physiol Behav. 2003;79:151-6.

88. Charil A, Laplante DP, Vaillancourt C, King S. Prenatal stress and brain development. Brain Res Rev. 2010;65:56-79.

89. Mueller BR, Bale TL. Sex-specific programming of offspring emotionality after stress early in pregnancy. J Neurosci. 2008;28: 9055-65.

90. Lucki I. The forced swimming test as a model for core and component behavioral effects of antidepressant drugs. Behav Pharmacol. 1997;8:523-32.

91. Brummelte S, Lieblich SE, Galea LA. Gestational and postpartum corticosterone exposure to the dam affects behavioral and endocrine outcome of the offspring in a sexually-dimorphic manner. Neuropharmacology. 2012;62:406-18.

92. Garardin P, Wendland J, Bodeau N, Galin A, Bialobos S, Tordjman S, et al. Depression during pregnancy: is the developmental impact earlier in boys? A prospective case-control study. J Clin Psychiatry. 2011;72:378-87.

93. Brummelte S, Schmidt KL, Taves MD, Soma KK, Galea LA. Elevated corticosterone levels in stomach milk, serum, and brain of male and female offspring after maternal corticosterone treatment in the rat. Dev Neurobiol. 2010;70:714-25.

94. Brummelte S, Pawluski JL, Galea LA. High post-partum levels of corticosterone given to dams influence postnatal hippocampal cell proliferation and behavior of offspring: a model of post-partum stress and possible depression. Horm Behav. 2006;50:370-82.

95. Schloesser RJ, Lehmann ML, Martinowich K, Manji H, Herkenham M. Environmental enrichment requires adult neurogenesis to facilitate the recovery from psychosocial stress. Mol Psychiatry. 2010;15:1152-63.

96. Cooke BM, Weathington JM. Human and animal research into sex-specific effects of child abuse. Horm Behav. 2014;65(4):41626.

97. Bourke CH, Neigh GN. Behavioral effects of chronic adolescent stress are sustained and sexually dimorphic. Horm Behav. 2011;60:112-20. This study showed that female sensitivity to psychosocial stress, relative to males, increases during adolescence.

98. McCormick CM, Robarts D, Kopeikina K, Kelsey JE. Longlasting, sex- and age-specific effects of social stressors on corticosterone responses to restraint and on locomotor responses to psychostimulants in rats. Horm Behav. 2005;48:64-74.

99. Kessler RC, McGonagle KA, Swartz M, Blazer DG, Nelson CB. Sex and depression in the National Comorbidity Survey. I: lifetime prevalence, chronicity and recurrence. J Affect Disord. 1993;29:85-96.

100. Nolen-Hoeksema S, Girgus JS. The emergence of gender differences in depression during adolescence. Psych Bull. 1994;115: 424-43.

101. Wilner P. Chronic mild stress (CMS) revisited: consistency and behavioural-neurobiological concordance in the effects of CMS. Neuropsychobiology. 2005;52:90-110.

102. Hasler G, Drevets WC, Manji H, Charney DS. Discovering endophenotypes for major depression. Neuropsychopharmacology. 2004;29:1765-81.

103. Steiner JE, Glaser D, Hawilo ME, Berridge KC. Comparative expression of hedonic impact: affective reactions to taste by human infants and other primates. Neurosci Biobehav Rev. 2001;25: 53-74.

104. Matthews K, Forbes N, Reid IC. Sucrose consumption as an hedonic measure following chronic mild stress. Physiol Behav. 1995;57:241-8.

105. Gronli J, Murison R, Bjorvatn B, Sorensen E, Portas CM, Ursin R. Chronic mild stress affects sucrose intake and sleep in rats. Behav Brain Res. 2004;150:139-47.

106. Nielsen CK, Arnt J, Sanchez C. Intracranial self-stimulation and scurose intake differ as hedonic measures following chronic mild stress: interstrain and inter-individual differences. Behav Brain Res. 2000;107:21-33.

107. Bielajew C, Konkle ATM, Merali Z. The effects of chronic mild stress on male Sprague-Dawley and Long Evans rats: I. Biochemical and physiological analyses. Behav Brain Res. 2002;136:583-92.

108. Gronli J, Murison R, Fiske E, Bjorvatn B, Sorensen E, Portas CM, et al. Effects of chronic mild stress on sexual behavior, locomotor activity and consumption of sucrose and saccharine solutions. Physiol Behav. 2005;84:571-7.

109. D'Aquila PS, Brain P, Willner P. Effects of chronic mild stress on performance in behavioural tests relevant to anxiety and depression. Physiol Behav. 1994;56:861-7.

110. Brotto LA, Gorzalka BB, LaMarre AK. Melatonin protects against the effects of chronic stress on sexual behaviour in male rats. Neuroreport. 2001;12:3465-9.

111. Hill MN, Hellemans KGC, Verma P, Gorzalka BB, Weinberg J. Neurobiology of chronic mild stress: parallels to major depression. Neurosci Biobehav Rev. 2012;36:2085-117.

112. Dalla C, Antoniou K, Drossopoulou G, Xagoraris M, Kokras N, Sfikakis A, et al. Chronic mild stress impact: are females more vulnerable? Neuroscience. 2005;135:703-14.

113. Dalla C, Antoniou K, Kokras N, Drossopoulou G, Papathanasiou $\mathrm{G}$, Bekris S, et al. Sex differences in the effects of two stress paradigms on dopaminergic neurotransmission. Physiol Behav. 2008;93:595-605.

114. Konkle ATM, Baker SL, Kentner AC, Barbagallo LSM, Merali Z, Bielajew C. Evaluation of the effects of chronic mild stressors on 
hedonic and physiological responses: sex and strain compared. Brain Res. 2003;992:227-38.

115. Grippo AJ, Sullivan NR, Damjanoska KJ, Crane JW, Carrasco GA, Shi J, et al. Chronic mild stress induces behavioral and physiological changes, and may alter serotonin $1 \mathrm{~A}$ receptor function, in male and cycling female rats. Psychopharmacology. 2005;179:769-80.

116. Duncko R, Kiss A, Skulteyova I, Rusnak M, Jezova D. Corticotropin-releasing hormone mRNA levels in response to chronic mild stress rise in male but not in female rats while tyrosine hydroxylase mRNA levels decrease in both sexes. Psychoneuroendocrinology. 2001;26:77-89.

117. Grippo AJ, Wu KD, Hassan I, Carter CS. Social isolation in prairie voles induces behaviors relevant to negative affect: toward the development of a rodent model focused on co-occurring depression and anxiety. Depression Anxiety. 2008;25:E17-26.

118. Ayensu WK, Pucilowski O, Mason GA, Overstreet DH, Rezvani AH, Janowsky DS. Effects of chronic mild stress on serum complement activity, saccharin preferences and corticosterone levels in Flinders lines of rats. Physiol Behav. 1995;57:165-9.

119. Garcia LS, Comim CM, Valvassori SS, Reus GZ, Stertz L, Kapczinski F, et al. Ketamine treatment reverses behavioral and physiological alterations induced by chronic mild stress in rats. Prog Neuropsychopharmacol Biol Psychiatry. 2009;33:450-5.

120. Reich CG, Taylor ME, McCarthy MM. Differential effects of chronic unpredictable stress on hippocampal CB1 receptors in male and female rats. Behav Brain Res. 2009;203:264-9.

121. Harris RBS, Zhou J, Youngblood BD, Smagin GN, Ryan DH. Failure to change exploration or saccharin preference in rats exposed to chronic mild stress. Physiol Behav. 1997;63:91-100.

122. De Jong TR, Harris BN, Perea-Rodriguez JP, Saltzman W. Physiological and neuroendocrine responses to chronic variable stress in male California mice (Peromyscus californicus): influence of social environment and paternal state. Psychoneuroendocrinology. 2013;38: 2023-33.

123. Koolhaas JM, Korte SM, De Boer SF, Van Der Vegt BJ, Van Reenen CG, Hopster H, et al. Coping styles in animals: current status in behavior and stress-physiology. Neurosci Biobehav Rev. 1999;23:925-35.

124. De Boer SF, Slangen JL, Van der Gugten J. Plasma catecholamine and corticosterone levels during active and passive shock-prod avoidance behavior in rats: effects of chlordiazepoxide. Physiol Behav. 1990;47:1089-98.

125. Trainor BC. Stress responses and the mesolimbic dopamine system: social contexts and sex differences. Horm Behav. 2011;60:457-69.

126. Miczek KA, Yap JJ, Covington HE. Social stress, therapeutics and drug abuse: preclinical models of escalated and depressed intake. Pharmacol Ther. 2008;120:102-28.

127. Russo SJ, Nestler EJ. The brain reward circuitry in mood disorders. Nat Rev Neurosci. 2013;14:609-25.

128. Huhman KL. Social conflict models: can they inform us about human psychopathology? Horm Behav. 2006;50:640-6.

129. Derntl B, Seidel E-M, Eickhoff SB, Kellermann T, Gur RC, Schneider F, et al. Neural correlates of social approach and withdrawal in patients with major depression. Soc Neurosci. 2011;6:482-501.

130. Moser JS, Huppert JD, Foa EB, Simons RF. Interpretation of ambiguous social scenarios in social phobia and depression: evidence from event-related brain potentials. Biol Psychol. 2012;89: 387-97.

131. Lara ME, Leader J, Klein DN. The association between social support and course of depression: is it confounded with personality? J Abnorm Psych. 1997;106:478-82.

132. Krishnan V, Han M-H, Graham DL, Berton O, Renthal W, Russo SJ, et al. Molecular adaptations underlying susceptibility and resistance to social defeat in brain reward regions. Cell. 2007;131:391-404
133. Jiang B, Wang WW, Wang F, Hu Z-L, Xiao J-L, Yang S, et al. The stability of NRsb in the nucleus accumbens controls behavioral and synaptic adaptations to chronic stress. Biol Psychiatry. 2013;74:145-55.

134. Lehmann ML, Geddes CE, Lee JL, Herkenham M. Urine scent marking (USM): a novel test for depressive-like behavior and a predictor of stress resiliency in mice. PLoS One. 2013;8:e69822.

135. Ver Hoeve E, Kelly G, Luz S, Ghanshani S, Bhatnagar S. Short-term and long-term effects of repeated social defeat during adolescence or adulthood in female rats. Neuroscience. 2013;249:63-73.

136. Bourke CH, Neigh GN. Exposure to repeated maternal aggression induces depressive-like behavior and increases startle in adult female rats. Behav Brain Res. 2012;227:270-5.

137. Shimamoto A, DeBold JF, Holly EN, Miczek KA. Blunted accumbal dopamine response to cocaine following chronic social stress in female rats: exploring a link between depression and drug abuse. Psychopharmacology. 2011;218:271-9. This study was one of the first to develop a social defeat stress protocol for females, allowing the application of this important approach to females as well as males.

138. Holly EN, Shimamoto A, DeBold JF, Miczek KA. Sex differences in behavioral and neural cross-sensitization and escalated cocaine taking as a result of episodic social defeat stress in rats. Psychopharmacology. 2012;224:179-88.

139. Huhman KL, Solomon MB, Janicki M, Harmon AC, Lin SM, Israel JE, et al. Conditioned defeat in male and female Syrian hamsters. Horm Behav. 2003;44:293-9.

140. Farruzzi AN, Solomon MB, Demas GE, Huhman KL. Gonadal hormones modulate the display of submissive behavior in socially defeated female Syrian hamsters. Horm Behav. 2005;47:569-75.

141. Silva AL, Fry WH, Sweeney C, Trainor BC. Effects of photoperiod and experience on aggressive behavior in female California mice. Behav Brain Res. 2010;208:528-34.

142. Trainor BC, Takahashi EY, Silva AL, Crean KK, Hostetler C. Sex differences in hormonal responses to social conflict in the monogamous California mouse. Horm Behav. 2010;58:506-12.

143. Trainor BC, Takahashi EY, Campi KL, Florez SA, Greenberg GD, Laman-Maharg A, et al. Sex differences in stress-induced social withdrawal: independence from adult gonadal hormones and inhibition of female phenotype by corncob bedding. Horm Behav. 2013;63:543-50.

144.• Trainor BC, Pride MC, Villalon Landeros R, Knoblauch NW, Takahashi EY, Silva AL, et al. Sex differences in social interaction behavior following social defeat stress in the monogamous California mouse (Peromyscus californicus). PLoS One. 2011;6:e17405. In this study, female California mice raised on corncob bedding showed a more male-typical phenotype when exposed to defeat stress later in life, suggesting that exposure to estrogen-like compounds during development affects responses to stress later in life.

145. Hinkelmann K, Botzenhardt J, Muhtz C, Agorastos A, Wiedemann K, Kellner M, et al. Sex differences of salivary cortisol secretion in patients with major depression. Stress. 2012;15:105-9.

146. Bremmer MA, Deeg DJ, Beekman AT, Penninx BW, Lips P, Hoogendijk WJ. Major depression in late life is associated with both hypo- and hypercortisolemia. Biol Psychiatry. 2007;62:479-86.

147. Moy SS, Nadler JJ, Young NB, Nonneman RJ, Segall SK, Andrade GM, et al. Social approach and repetitive behavior in eleven inbred mouse strains. Behav Brain Res. 2008;191:118-29.

148. Greenberg GD, Laman-Maharg A, Campi KL, Voigt H, Orr VN, Simion C, et al. Sex differences in stress-induced social withdrawal: role of brain derived neurotrophic factor in the bed nucleus of the stria terminalis. Front Behav Neurosci. 2014;7:223.

149. Seidel E-M, Habel U, Finkelmeyer A, Schneider F, Gur RC, Derntl B. Implicit and explicit behavioral tendencies in male and female depression. Psychiatry Res. 2010;177:124-30. 
150. Markaverich BM, Alejandro MA, Markaverich D, Zitzow L, Casajuna N, Camarao N, et al. Identification of an endocrine disrupting agent from corn with mitogenic activity. Biochem Biophys Res Commun. 2002;291:692-700.

151. Villalon Landeros R, Yoo HJ, Morisseau C, Fu S, Hammock $\mathrm{BD}$, Trainor BC. Corncob bedding reverses the effects of estrogens on aggressive behavior and reduces estrogen receptor alpha expression in the brain. Endocrinology. 2012;153:94953.

152. Markaverich BM, Crowley J, Rodriguez M, Shoulars K, Thompson T. Tetrahydrofurandiol stimulation of phospholipase A2, lipoxygenase, and cyclooxygenase gene expression and MCF-7 human breast cancer cell proliferation. Environ Health Perspect. 2007;115:1727-31.

153. Amateau SK, McCarthy MM. Induction of PGE(2) by estradiol mediates developmental masculinization of sex behavior. Nat Neurosci. 2004;7:643-50.

154. McCarthy MM, Wright CL, Schwarz JM. New tricks by an old dogma: mechanisms of the organizational/activational hypothesis of steroid-mediated sexual differentiation of brain and behavior. Horm Behav. 2009;55:655-65.

155. D’Ursi P, Salvi E, Fossa P, Milanesi L, Rovida E. Modelling the interaction of steroid receptors with endocrine disrupting chemicals. BMC Bioinformatics 2005;6 Suppl 4:S10.

156. Li Y, Luh CJ, Burns KA, Arao Y, Jiang Z, Teng CT, et al. Endocrine-disrupting chemicals (EDCs): in vitro mechanism of estrogenic activation and differential effects on ER target genes. Environ Health Perspect. 2013;121:459-66. 466e1-6.

157. Teng C, Goodwin B, Shockley K, Xia M, Huang R, Norris J, et al. Bisphenol A affects androgen receptor function via multiple mechanisms. Chem Biol Interact. 2013;203:556-64.

158. Clairardin SG, Paitz RT, Bowden RM. In ovo inhibition of steroid metabolism by bisphenol-A as a potential mechanism of endocrine disruption. Proc Biol Sci. 2013;280:20131773.
159. Yaoi T, Itoh K, Nakamura K, Ogi H, Fujiwara Y, Fushiki S. Genome-wide analysis of epigenomic alterations in fetal mouse forebrain after exposure to low doses of bisphenol A. Biochem Biophys Res Commun. 2008;376:563-7.

160. Panagiotidou E, Zerva S, Mitsiou DJ, Alexis MN, Kitraki E. Perinatal exposure to low-dose bisphenol A affects the neuroendocrine stress response in rats. J Endocrinol. 2014;220:207-18.

161. Palanza P, Howdeshell KL, Parmigiani S, vom Saal FS. Exposure to a low dose of bisphenol A during fetal life or in adulthood alters maternal behavior in mice. Environ Health Perspect. 2002;110: 415-22.

162. Goel N, Bale TL. Examining the intersection of sex and stress in modelling neuropsychiatric disorders. J Neuroendocrinol. 2009;21:415-20.

163. Bertolasio J, Fyfe S, Snyder BW, Davis AM. Neonatal injections of methoxychlor decrease adult rat female reproductive behavior. Neurotoxicology. 2011;32:809-13.

164. Carbone S, Ponzo OJ, Gobetto N, Samaniego YA, Reynoso R, Scacchi $\mathrm{P}$, et al. Antiandrogenic effect of perinatal exposure to the endocrine disruptor di-(2-ethylhexyl) phthalate increases anxietylike behavior in male rats during sexual maturation. Horm Behav. 2013;63:692-9.

165. Schultz MM, Bartell SE, Schoenfuss HL. Effects of triclosan and triclocarban, two ubiquitous environmental contaminants, on anatomy, physiology, and behavior of the fathead minnow (Pimephales promelas). Arch Environ Contam Toxicol. 2012;63: 114-24.

166. Knapp R, Marsh-Matthews E, Vo L, Rosencrans S. Stress hormone masculinizes female morphology and behaviour. Biol Lett. 2011;7:150-2.

167. Frederick P, Jayasena N. Altered pairing behaviour and reproductive success in white ibises exposed to environmentally relevant concentrations of methylmercury. Proc Biol Sci. 2011;278:1851-7. 